\title{
Impacts and Predictions of Coastal Change during Hurricanes
}

\section{Communities at Risk}

Beaches serve as a natural barrier between the ocean and inland communities, ecosystems, and resources. These dynamic environments move and change in response to winds, waves, and currents. During a powerful hurricane, changes to beaches can be large, and the results are sometimes catastrophic. Lives are lost, communities are destroyed, and millions of dollars are spent on rebuilding. There is a clear need to identify areas of our coastline that are likely to experience extreme and devastating erosion during a hurricane. It is also important to determine risk levels associated with development in areas where the land shifts and moves with each landfalling storm. The U.S. Geological Survey (USGS) provides scientific support for hurricane planning and response. Using observations of beach changes and models of waves and storm surge, we are predicting how the coast will respond to hurricanes and identifying areas vulnerable to extreme coastal changes.
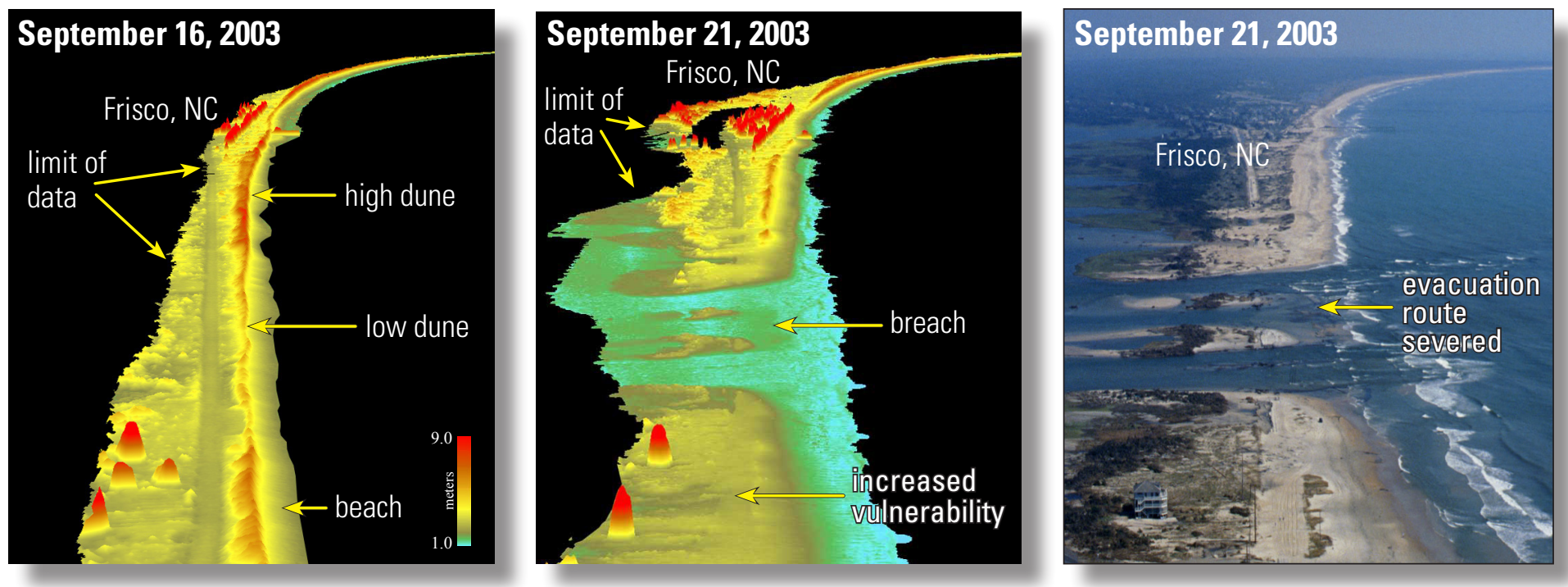

\section{Evacuation routes blocked or severed}

Waves overtopping a dune can transport sand inland, covering roads and blocking evacuation or emergency response. If storm surge fully inundates a barrier island, currents flowing across the island can create a breach, or new inlet, completely severing evacuation routes. Waves and surge during the 2003 landfall of Hurricane Isabel left a 500-mwide breach that cut road transportation to and from the village of Hatteras, NC (above).

\section{Coastal vulnerability increased}

When sand dunes are eroded completely, inland structures are exposed to storm surge and waves. The absence of dunes also allows water to flow across the island, potentially increasing storm surge in the back bay and on the mainland. During Hurricane Isabel, the protective sand dunes near the breach were destroyed, increasing island vulnerability to future storms (above).

\section{Structures undermined}

Structures built on top of sand dunes can be undermined by wave attack and erosion during a storm. During Hurricane Ivan in 2004, a five-story condominium in Orange Beach, AL, collapsed after the sand dune supporting its foundation was eroded (right).
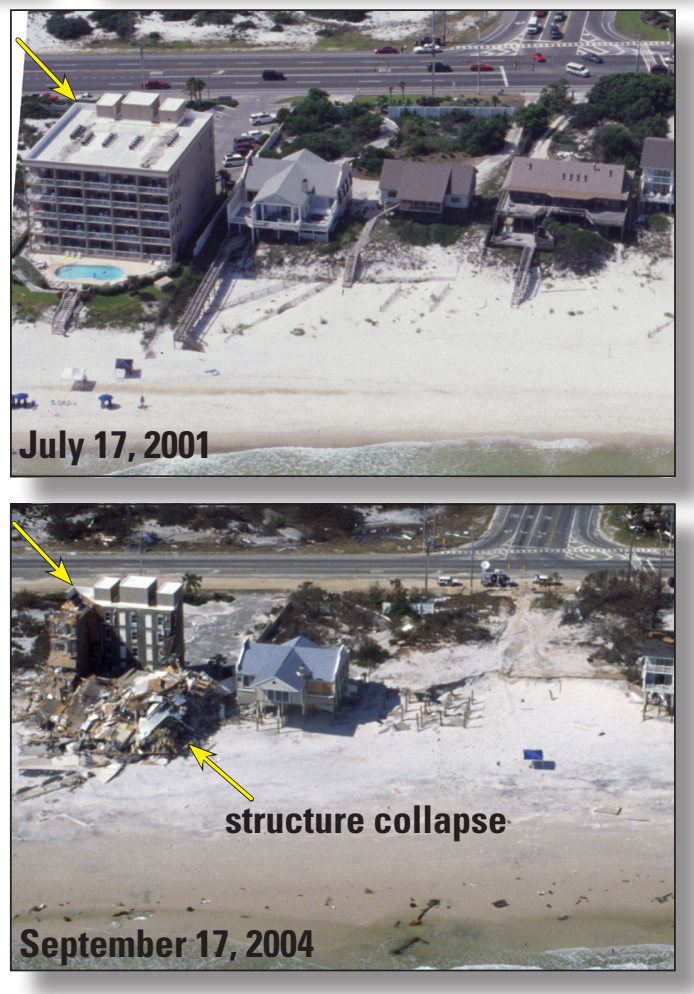


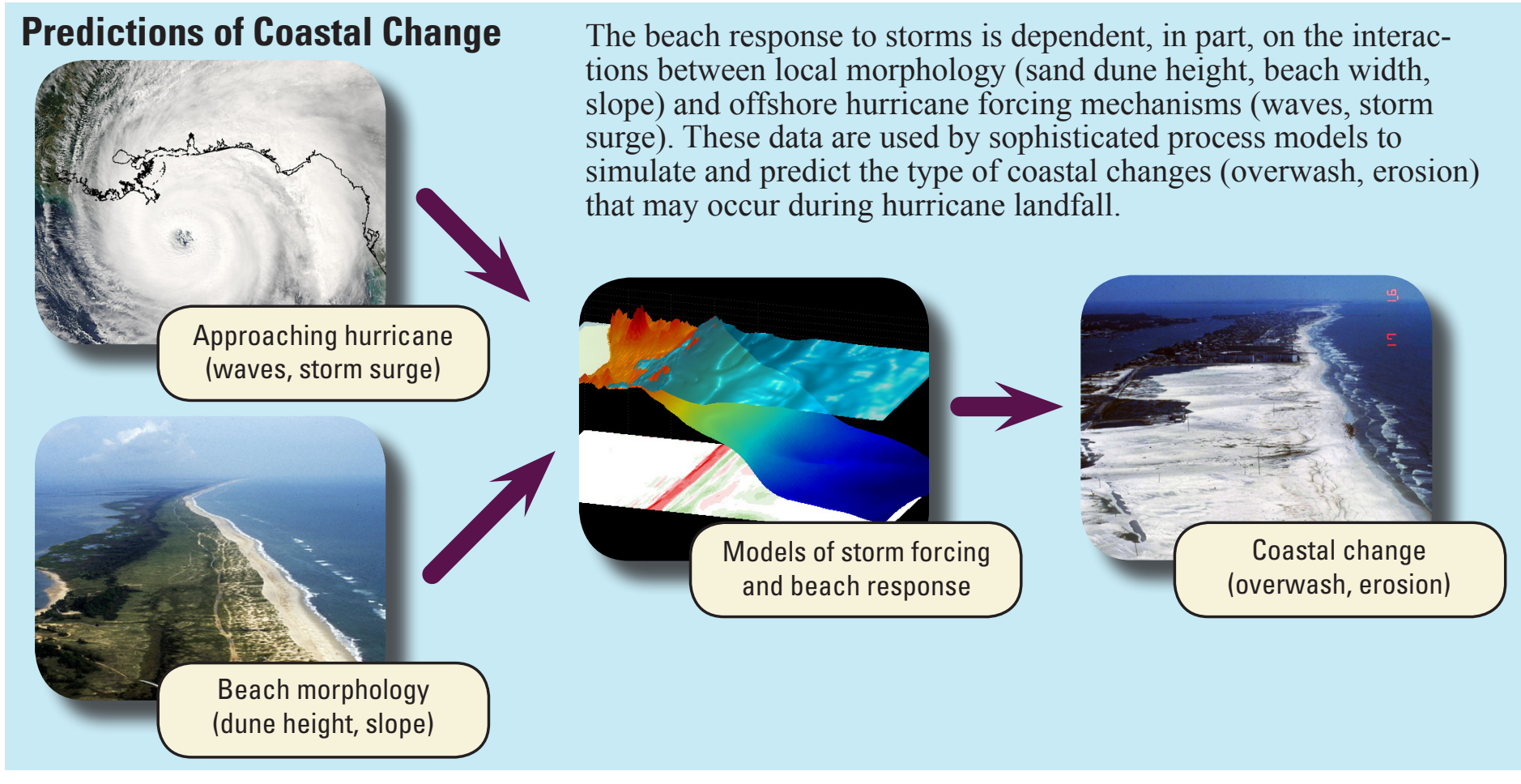

\section{Science for Decision Makers:}

Forecast of inundation and observations of erosion on the Bolivar Peninsula, TX, during Hurricane lke (2008)
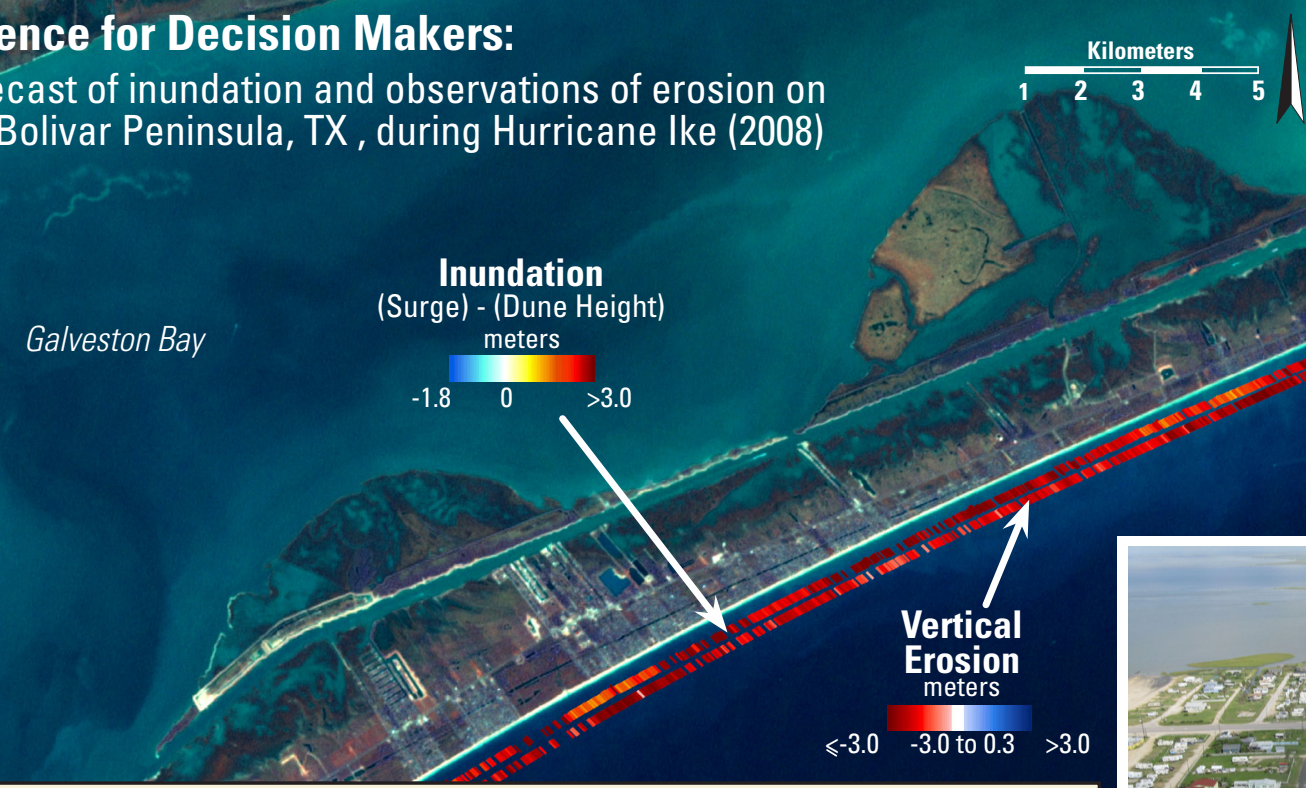

\section{Inundation and Beach Erosion}

The USGS predicted that the beaches on the Bolivar Peninsula, TX, would be inundated by storm surge during Hurricane Ike and would experience large magnitudes of erosion. The map above shows predictions of inundation exceeding $2 \mathrm{~m}(6.5 \mathrm{ft})$ along much of the coast. Comparisons of pre- and post-storm photography (right) reveal extensive structural damage as well as signs of water flow over the island and subsequent erosion. Measurements of elevation changes due to the hurricane indicate widespread erosion and an almost complete destruction of the seaward dune, likely increasing vulnerability to future storms. Accurate forecasts of the coastal response to hurricanes play an essential role in successful mitigation and resiliency planning.

storm came ashore.

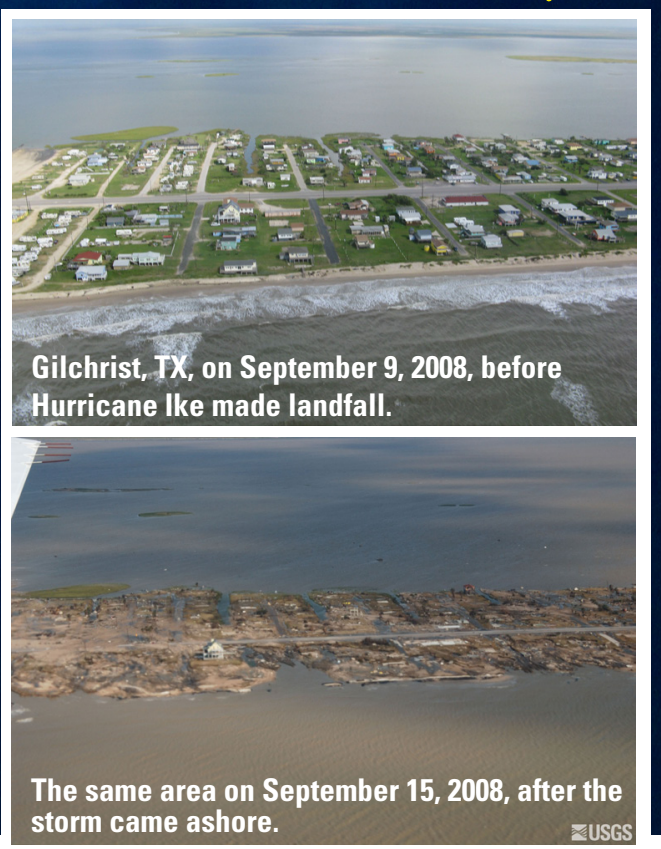

\begin{tabular}{|ll}
\hline For additional information, please contact: & Hilary Stockdon, hstockdon@usgs.gov \\
& Abby Sallenger, asallenger@usgs.gov
\end{tabular}

U.S. Geological Survey http://coastal.er.usgs.gov/hurricanes

St. Petersburg Science Center St. Petersburg, FL 33701 